\title{
Transposition with auditory stimuli following successive discrimination training
}

\author{
MICHAEL BLAZ \\ University of Kentucky, Lexington, Kentucky 70506 \\ and \\ JERAL R. WILLIAMS \\ Illinois State University, Normal, Illinois 61761
}

\begin{abstract}
An investigation was performed to examine whether responding to auditory stimuli would be to relative, or to absolute properties of stimuli. The design was a replication of previous research, with additional control of a possible stimulus intensity effect. Rats were trained to respond to one of two tones differing in intensity, and later tested to determine whether transposition occurred. Transposition was reliable $(p<.05)$ for each subject, both when the correct transpositional stimulus was the more intense and when it was the less intense of two stimuli.
\end{abstract}

Blue and Hegge (1965) reported successful auditory transposition in rats utilizing intensity as the stimulus dimension which was transposed. These authors reinforced responses to a $55-\mathrm{dB}$ tone for all subjects. Individual rats each received a different and constant nonreinforced stimulus consisting of one of several tones which ranged from 15 to $50 \mathrm{~dB}$. After 7 days of training, all rats were presented with a new pair of stimuli each of which was $45 \mathrm{~dB}$ more intense than the original stimulus.

Blue and Hegge assumed successful transposition if a subject responded more frequently to the $100-\mathrm{dB}$ stimulus than to the other new stimulus. Using this criterion, three of four subjects exhibited transposition. A possible confound in the paradigm employed by Blue and Hegge is the fact that the correct stimulus both during training and during subsequent testing was always the more intense stimulus of the pair.

In the present research, two rats were trained and tested using the more intense stimulus as the "correct" transpositional test stimulus; in effect, then an attempt at replication of the Blue and Hegge finding. Two additional subjects were, however, trained and tested under conditions in which the less intense stimulus was the correct transpositional stimulus.

\section{METHOD}

\section{Subjects and Apparatus}

Subjects were four female albino rats (Holtzman Animal Farms, Madison, Wisconsin, 53706) approximately 4 months of age. A Lehigh Valley Electronics small rodent chamber (Model 143-04) equipped with liquid reinforcement was placed inside a sound attenuating chamber. Auditory stimuli were generated by a Hewlett-Packard Model 200A audio oscillator and amplified with a Pioneer Model SA-800 amplifier. The tones $(400 \mathrm{~Hz}$ verified with a Hewlett-Packard 5300-A measuring system utilizing a 5304-A timer counter subbase) were delivered to the chamber at $60 \mathrm{~dB}$ and in some instances attenuated to 50

This paper is sponsored by Leonard Schmaltz who takes full editorial responsibility for it. and $40 \mathrm{~dB}$. A Hewlett-Packard Model 1509-B condenser microphone was suspended in the chamber, and intensity was calibrated with a Hewlett-Packard (8062-A) sound level meter.

\section{Procedure}

All rats were deprived of water for $23 \mathrm{~h}$ prior to being placed in the operant chamber. Preliminary training took approximately 3 weeks. Subjects were first shaped to make the barpress response, then they were placed on a VI 5-sec (range 1-10 sec) schedule of reinforcement until all animals were responding at moderate rates.

Following preliminary training, subjects were randomly assigned to one of four conditions. One rat was reinforced for responding during presentation of a $50-\mathrm{dB}$ tone and not rewarded while a $40-\mathrm{dB}$ tone was presented. The presentation of a tone was for a $15-\mathrm{sec}$ period. Which of the two tones was presented was determined by random assignment of a tone to a 15 -sec time block with the restriction that there be an equal amount of total time for presentation of each tone. Each training session was $12 \mathrm{~min}$ in duration. At no time during the entire session was a tone not present. Thus the reward was available for $6 \mathrm{~min}$ and not available for $6 \mathrm{~min}$. A second subject was reinforced when the $40-\mathrm{dB}$ tone was in effect and not reinforced when the $50-\mathrm{dB}$ tone was present. Two additional subjects were trained as above with the exception that the presentation of tones was for 30 -sec intervals.

After 13 training sessions, all subjects were tested for transposition on 2 consecutive days, by increasing the intensity of each tone by $10 \mathrm{~dB}$. Thus, the tones were $50 \mathrm{~dB}$ and $60 \mathrm{~dB}$. The reward was not available during these days, although the tones were presented. On Day 1, tones were alternated on a 15-sec schedule for $2 \mathrm{~min}$ and on Day 2 the tones were alternated on a 30 -sec schedule. In order to prevent extinction, Training Sessions 14 and 15 with the original stimulus conditions occurred on consecutive days between Test Days 2 and 3. On Test Day 3, transposition testing was resumed for 2 days with the same conditions as Test Days 1 and 2 except testing was for 6 min. Training Sessions 16 and 17 and Test Sessions 5 and 6 followed Test Day 4 and were identical to Training Sessions 14 and 15, and Test Sessions 3 and 4.

\section{RESULTS AND DISCUSSION}

In Table 1 it can be seen that, in each of the final six sessions before transposition testing, the subjects were 
making more responses in the presence of the rewarded stimulus than in the presence of the nonrewarded stimulus. Individual $t$ tests comparing the number of responses when the reward was available to the number of responses when the reward was not available revealed significant differences for all four subjects; $\mathrm{t}(5)=10.79$, $6.76,5.93$, and $6.23(\mathrm{p}<.05)$ for subjects $50-15,40-15$, 50-30, and 40-30, respectively.

For the transposition results, it can be seen in Table 2 that subjects 50-15 and 40-30 emitted more responses appropriate for transpositional than for absolute responding during all six test sessions. The 40-15 and 50-30 subjects responded similarly during five of six sessions. Thus, out of 24 possible sessions in 22 periods transposition responses occurred more frequently than absolute responses. In terms of total responses, 468 were transpositional and 298 were absolute.

In order to test for replication and for control of intensity of the correct stimulus, the results were analyzed separately. A single factor repeated measures analysis of variance comparing transpositional to absolute responding for subjects 50-15 and 50-30 yielded a significant type of response factor $[F(1,11)=$ $11.05, \mathrm{p}<.05$ ]. Thus, Blue and Hegge's (1965) result showing transpositional responding when the shift is with the most intense auditory stimulus was replicated. In addition, the same comparison for subjects $40-15$ and

Table 1

Number of Responses During Training

\begin{tabular}{|c|c|c|c|c|c|c|c|c|}
\hline \multirow{3}{*}{$\begin{array}{l}\text { Day } \\
\text { of } \\
\text { Train- } \\
\text { ing }\end{array}$} & \multicolumn{8}{|c|}{ Subject } \\
\hline & \multicolumn{2}{|c|}{$50-15$} & \multicolumn{2}{|c|}{$40-15$} & \multicolumn{2}{|c|}{$50-30$} & \multicolumn{2}{|c|}{$40-30$} \\
\hline & RA* & RNA $\dagger$ & RA & RNA & RA & RNA & RA & RNA \\
\hline 8 & 147 & 117 & 184 & 103 & 93 & 30 & 137 & 69 \\
\hline 9 & 145 & 122 & 203 & 109 & 122 & 38 & 125 & 61 \\
\hline 10 & 141 & 108 & 160 & 69 & 78 & 18 & 116 & 23 \\
\hline 11 & 186 & 142 & 241 & 147 & 166 & 43 & 92 & 55 \\
\hline .12 & 152 & 110 & 205 & 166 & 81 & 27 & 70 & 34 \\
\hline 13 & 133 & 94 & 129 & 89 & 170 & 30 & 155 & 60 \\
\hline 14 & 169 & 86 & 192 & 86 & 171 & 31 & 102 & 38 \\
\hline 15 & 123 & 110 & 195 & 95 & 50 & 39 & 54 & 33 \\
\hline 16 & 144 & 108 & 182 & 111 & 104 & 21 & 92 & 37 \\
\hline 17 & 90 & 63 & 115 & 49 & 37 & 14 & 47 & 18 \\
\hline
\end{tabular}

* $R A$ represents reward available.

$\dagger R N A$ represents reward not available.
Table 2

Number of Responses During Testing

\begin{tabular}{|c|c|c|c|c|c|c|c|c|}
\hline \multirow{3}{*}{$\begin{array}{l}\text { Day of } \\
\text { Testing } \\
\end{array}$} & \multicolumn{8}{|c|}{ Subject } \\
\hline & \multicolumn{2}{|c|}{$50-15$} & \multicolumn{2}{|c|}{$40-15$} & \multicolumn{2}{|c|}{$50-30$} & \multicolumn{2}{|c|}{$40-30$} \\
\hline & $\mathrm{T}^{*}$ & $\mathrm{NT} \dagger$ & $\mathrm{T}$ & NT & $T$ & NT & $\mathrm{T}$ & NT \\
\hline 1 & 35 & 29 & 31 & 36 & 26 & 10 & 13 & 10 \\
\hline 2 & 20 & 18 & 16 & 3 & 8 & 7 & 8 & 5 \\
\hline 3 & 54 & 31 & 20 & 10 & 13 & 5 & 25 & 16 \\
\hline 4 & 29 & 18 & 16 & 9 & 4 & 7 & 22 & 16 \\
\hline 5 & 17 & 8 & 22 & 7 & 10 & 4 & 27 & 18 \\
\hline 6 & 12 & 10 & 23 & 9 & 2 & 0 & 15 & 5 \\
\hline
\end{tabular}

${ }^{*} T$ represents the transpositional stimulus.

†NT represents the nontranspositional stimulus.

40-30 yielded a significant type of response factor $[\mathrm{F}(1,11)=17.48, \mathrm{p}<.05]$. Thus, transpositional responding occurred when intensity of the correct stimulus was the least intense stimulus. The possible effects of the differences in the stimulus presentation intervals on responding were not analyzed. The variation in interval length (i.e., $15 \mathrm{sec}$ and $30 \mathrm{sec}$ ) was included to increase generalizability and not because the interval length was of designed interest.

The results continue to support the generalization that transpositional responding will occur with auditory stimuli using intensity as the discriminative dimension. However with subjects 40-30 and 40-15 the support for transpositional responding must still be guarded, because even though the transpositional test stimulus was the same as the nonrewarded stimulus during training, the transpositional stimulus was also the closest in intensity to the previously rewarded stimulus condition. Therefore, generalization of the correct absolute response would also be strongest. An even more thorough test would be to replicate the present design and to include conditions in which training is to the least intense stimulus and the shift during the transposition testing is to tones that are lower in intensity than during training.

\section{REFERENCES}

Blue, S., \& Hegge, F. W. Transposition of a stimulus generalization gradient along an auditory intensity continuum. Psy chonomic Science, 1965, 3, 201-202.

(Received for publication January 30, 1975.) 